\title{
ESCRILEITURAS TRADUTÓRIAS: REINVENÇÃO EMPÍRICA DO ARQUIVO
}

\author{
TRANSLATING READING-WRITINGS: EMPIRICAL REINVENTION OF THE FILE
}

LECTOESCRITURAS PARA TRADUCIR: REINVENCIÓN EMPÍRICA DEL ARCHIVO

Maria Idalina Krause de Campos $^{1}$, Fabiane Olegário², Sandra Mara Corazza ${ }^{3}$

\section{RESUMO}

Este artigo busca pensar o arquivo como um plano de pensamento aberto a ações tradutórias em educação. Toma a tradução de um texto de partida atravessado por movimentos-fluxos como via de escrileituras que promovem a reinvenção empírica de dados e que se tornam uma potência afirmadora no campo da educação. Nesse processo, o educador-tradutor é tomado por uma força intensiva que faz variar o existente, passando a produzir novas conexões imaginativas que se cruzam e se atualizam em ações experimentais atravessadas por elementos filosóficos, científicos, artísticos e literários. Tais encontros possibilitam práticas afirmativas da docência, visto que o educador-tradutor não se limita a reproduzir os conhecimentos originais, pois, à medida que traduz, atribui novos e múltiplos sentidos ao próprio texto de partida e por esse meio passa a expressar e a construir novas realidades articuladas com uma poética de escrita. Sendo assim, o conhecimento contido em um determinado arquivo torna-se possibilidade de invenção e de ficção, porque se constitui como um suporte gerativo e didático para novos saberes que são experimentados cotidianamente no ensino e na educação contemporânea.

PALAVRAS-CHAVE: Escrileituras. Educação. Tradução. Arquivo.

\begin{abstract}
This paper attempts to think about the file as a thought plan that is open to translating actions in education. It regards the translation of a source text crossed by flow-movements as via of reading-writings that promote the empirical reinvention of data and become an affirming potency in the field of education. In this process, the translator-educator is taken by an intensive force that makes the existent vary, thus producing new imaginative connections that intersect and are updated in experimental actions crossed by philosophical, scientific, artistic and literary elements. Such encounter enables affirmative teaching practices, once the translator-educators are not bound to reproduce the original knowledges, as they attribute new and multiple meanings to the source text while translating, thus expressing and constructing new realities articulated with a poetics of writing. Hence, the knowledge contained in a certain file becomes a possibility of invention and fiction, as it is a generative and didactical support for new knowledges daily experienced in contemporary teaching and education.
\end{abstract}

KEYWORDS: Reading-writings. Education. Translation. File.

\footnotetext{
${ }^{1}$ Doutorado em Educação - Universidade Federal do Rio Grande do Sul (UFRGS) - Porto Alegre, RS - Brasil. Professor colaborador - Universidade Federal do Rio Grande do Sul , Brasil. E-mail: idalinakrause@yahoo.com.br

${ }^{2}$ Doutorado em Educação - Universidade Federal do Rio Grande do Sul (UFRGS) - Porto Alegre, RS - Brasil. Professora Assistente da Universidade do Vale do Taquari (UNIVATES) - Lajeado, RS - Brasil. E-mail: fabiole@univates.br

${ }^{3}$ Doutorado em Educação - Universidade Federal do Rio Grande do Sul (UFRGS) - Porto Alegre, RS - Brasil. Professor Titular - Universidade Federal do Rio Grande do Sul (UFRGS) - Porto Alegre, RS - Brasil. E-mail: sandracorazza@terra.com.br
}

Submetido em: 08/07/2017 - Aceito em: 09/01/2018

(C) ETD- Educação Temática Digital $\quad$ Campinas, SP $\quad$ v.20 $\quad$ n.4 $\quad$ p. 963-978 $\quad$ out./dez. 2018




\section{RESUMEN}

Este artículo busca entender el archivo como un plan de pensamiento abierto a las acciones de traducción en la educación. Toma la traducción desde un texto de partida, atravesado por movimientos-flujos como vía de lectoescrituras que promueven la reinvención empírica de datos y que se convierte en una potencia afirmadora en el campo de la educación. En este proceso, el educador-traductor no se limita a reproducir los conocimientos originales, ya que, a medida que traduce, atribuye nuevos y múltiples sentidos al propio texto de partida, y por ese medio pasa a expresar y a construir nuevas realidades articuladas con una poética de escrita. Siendo así, el conocimiento contenido en un determinado archivo se torna una posibilidad de invención y de ficción, porque se constituye como un soporte generativo y didáctico para nuevos saberes que son experimentados cotidianamente en el enseño y en la educación contemporánea.

PALABRAS CLAVE: Lectoescrituras. Educación. Traducción. Archivo.

\section{PLANO DE PENSAMENTO}

Este artigo aborda e pensa o arquivo como um plano de pensamento aberto a ações tradutórias em educação. Em tal plano, a tradução é vista como uma potência afirmadora por sua possibilidade de reinventar os arquivos instituídos como textos originais. Tal movimento de reinvenção pressupõe uma vontade de potência para fazer variar o existente por meio de processos de leitura e de escrita tradutórios. A escrileitura - escrita e leitura é uma ferramenta da qual o educador se utiliza para lançar sobre um texto de partida novos movimentos-fluxo. Por isso, partimos da leitura aberta às interferências do leitor e da escrita como a manifestações concretas do ato de atribuir sentidos ao texto. Para Barthes (2005, p.15), a leitura e a escrita são tomadas como "movimento de troca recíproca; talvez seja isso a Força de toda a criação". Como práticas simultâneas - ler e escrever num único gesto - não havendo nessa relação nenhuma primazia e sequer privilégio exclusivo de uma sobre a outra. Portanto, as práticas de ler e escrever se relacionam, primeiramente com o texto de partida, para então, reivindicar a produção do texto de chegada; sendo necessário o encadeamento de regras próprias que visam às condições de "fazer a língua se mover com palavras cada vez mais sóbrias e uma sintaxe cada vez mais fina" (DELEUZE; PARNET, 1998, p.72). Isso possibilita a proliferação de novos saberes, na medida em que passa a produzir novas conexões imaginativas que se cruzam e se atualizam em ações experimentais atravessadas por elementos filosóficos, científicos, artísticos e literários.

O desafio que se impõe no texto é tomar a tradução poética como recriação por meio da transcriação e da reimaginação a partir das formulações teóricas de Haroldo de Campos (2013) e fazê-la deslocar-se para o campo da educação, para assim pensar o educador como um tradutor de arquivos capaz de constituir novas didáticas inventivas de maneira transcriadora. Sendo assim, o educador é aquele que transcria os arquivos didáticos, ou seja, por meio de ações tradutórias, faz transbordar novos sentidos provenientes do original. Tal medida promove também a proliferação de encontros variados, sejam eles: transculturais, transdisciplinares, translinguísticos e transsemióticos.

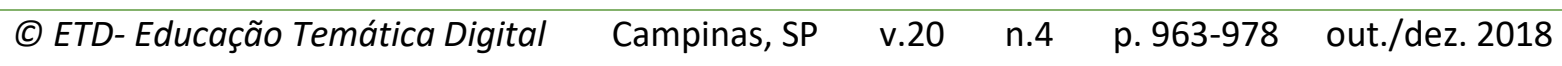


Tais encontros abrem possibilidades afirmativas na prática da docência, visto que o educador-tradutor não se limita a reproduzir os conhecimentos originais, pois, à medida que traduz, atribui novos e múltiplos sentidos ao próprio texto de partida e por esse meio passa aexpressar e a construir novas realidades articuladas com uma poética de escrita. Sobretudo, pensamos que o conhecimento contido em um determinado arquivo se torna possibilidade de invenção e de ficção, constituindo-se como um suporte gerativo e didático para novos saberes que são experimentados no dia a dia no ensino e na educação contemporânea.

O texto divide-se em quatro tópicos: 1) A ação tradutória que observa o movimento de recirculação textual; 2) O arquivo visto como suporte gerativo para novos saberes; 3) A escrileitura que promove a reinvenção empírica de dados, tornando-se uma potência afirmadora no campo da educação; 4) O fazer poético afirma o pensamento de Paul Valéry como possível para desenvolver pesquisas no campo da educação.

O texto desloca-se por esses tópicos e, com eles, deseja abrir caminho para o debate a respeito da pesquisa e de modos de conceber o arquivo como um plano de pensamento aberto a ações tradutórias, para um pensar potente e aventureiro no ensino e na educação contemporânea.

\section{AÇÃO TRADUTÓRIA}

De acordo com Campos (2008, p.183), a ação tradutória é uma "operação radical, cuja virtude transfusora" funciona no instante em que passa a vivificar as matérias contidas na fonte original, o que, concomitantemente, nutre o tradutor em um movimento de recirculação textual novo. Tal possibilidade ocorre porque todo e qualquer conhecimento que nos propomos passa necessariamente pela linguagem.

Tomando o argumento de Campos como válido, o educador, na medida em que passa a promover ação tradutória sobre determinado arquivo, começa a despir-se da imagem de reprodutor de conhecimentos, pois suas ações pedagógicas abordam um pensar na contramão daquilo que é posto como certezas absolutas e que constitui práticas ditas verdadeiras. Portanto, distancia-se das imagens dogmáticas do pensamento ou dogmas originais.

Além disso, a postura do educador-tradutor implica um pensar com renovação, almejando a criação de um lugar vivível e propício para traduzir. Os conhecimentos que compõem o arquivo original não mais se pré-configuram como simples transmissão na esfera do já dado, do já conhecido, incidindo sobre eles o olhar da suspeita que os faz divergir à medida que novos problemas sobre eles são postulados.

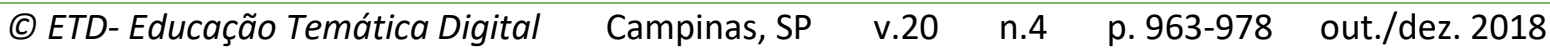


Tais problemáticas, uma vez erigidas, ocorrem porque o educador-tradutor aposta na escrita e na leitura como uma maneira profícua e afirmativa para novas interpretações, o que acarreta múltiplos sentidos decorrentes de uma ação efetiva sobre o texto. Assim, leitura e escrita são ocorrências singulares, não cabendo mais nesse processo à imagem do educador como uma corrente de transmissão automática de significação inequívoca, ou seja, o educador que se põe a serviço como um transmissor literal do conteúdo contido no arquivo.

$\mathrm{Na}$ contramão desse tipo reativo de educação, o texto é avesso à literalidade tradutora do original e, portanto, quer possibilitar outras composições textuais afeitas a novas configurações, desenhos e paisagens. Desse modo, esses compósitos de escrita e leitura (escrileitura) rabiscam novos trajetos e traços que forçam deslocamentos no modo de pensar dogmático; são giros de uma malha intelectiva que buscam outras dimensões possíveis e deixam escoar um pensamento em fluxo criador de planos geométricos constituídos de linhas transversais à educação.

Segundo Paz (2009, p.19), "aprender a falar é aprender a traduzir". Desde nosso nascimento até nossa morte, lidamos com a linguagem e, por via de consequência, com a tradução. Observa-se, assim, que a tradução serve como um dispositivo fônico e importante como meio de expressão, pois emite vozes.

Então, poderíamos questionar: com quais vozes nos deparamos ao traduzir um arquivo? Por certo, com muitas e múltiplas vozes, e, no instante em que passamos a traduzilas, há nesse processo uma "invenção deliberada e não testemunho de uma verdade (mais verdadeira), de uma origem (mais original)" (OLIVEIRA, 2014, p.70). Além disso, há o exercício vivível de transcriação do original em um fazer aberto à descoberta, aos enigmas e às surpresas.

\section{ARQUIVO}

A transcriação é compreendida como uma atividade implicada na própria vida, como um fazer imanente e errante. Nesse sentido, o educador é um tradutor e construtor de dissonâncias e assimetrias textuais favoráveis à renovação das vozes contidas no original. À sua maneira, o educador cria práticas didáticas, na medida em que mostra o seu potencial de criação, tomado por um ponto de vista tradutor que reinventa vozes ainda não consideradas.

É importante salientar que, de modo corriqueiro, o arquivo é compreendido como um local de armazenamento de documentos - fotografias, cartas, registros oficiais - cujo objetivo é conservar uma memória passada que pode, no presente, ser acessada pelos sujeitos. Nessa perspectiva, é muito comum, imaginar o arquivo como um depósito de

\begin{tabular}{|c|c|}
\hline Educação Temática Digital & $963-978$ \\
\hline
\end{tabular}


documentos amarelados, carcomidos e dispostos em alguma pilha ligeiramente empoeirada (FARGE, 2009).

$\mathrm{O}$ arquivo, a partir do momento em que é examinado como texto - unidade de sentido -, passa a ser descontruído; talvez seja por isso que ele jamais poderá fechar-se. A noção aberta de arquivo faz proliferar múltiplas inscrições, que se fazem em meio a outras tantas; à medida que o arquivo se distancia da origem, afirma a força tradutória. Esse fluxo de inscrições não significa repetir o passado: "trata-se do futuro, a própria questão do futuro, a questão de uma resposta, de uma promessa e de uma responsabilidade para o amanhã" (DERRIDA, 2001, p.50).

$\mathrm{O}$ arquivo é texto, sendo que a sua existência depende do que fizermos dele no momento presente. $\mathrm{O}$ arquivo vivo e aberto relaciona-se com o futuro, o que requer necessariamente a sua montagem/desmontagem/remontagem; no entanto, essa atividade só pode ser acessada via leitura e escrita do material arquivado. O tradutor lida com matérias advindas de outra instância, tanto espacial, quanto temporal. É certo que, em se tratando de arquivo aberto, estaremos sempre entrelaçados no "presente passado, presente atual e presente futuro" (BIRMAN, 2008, p.110).

Não sendo possível fixá-lo e tampouco tratá-lo como inerte, o arquivo lança-se na aventura de ser novamente suplementado. Há nisso tudo uma forte suspeita de que um arquivo não exista enquanto arquivo-morto. Tudo nos leva a crer que o arquivo tem vida própria, cabe a quem sobre ele se debruça proceder a tais capturas de vida para assim passar a transcriá-lo. Logo, a sobrevida de um arquivo depende dos processos tradutórios, de práticas de leitura e de escrita que atribuem sentidos ao texto original. Desse modo, os sentidos produzidos pela via da leitura e da escrita são recriados pelo tradutor, que insiste em tocar o intocável, desestabilizar o estável e penetrar no impenetrável do arquivo.

O arquivo não faz referência a um depósito de memória sem ser lesionado por borrões, rasuras e esquecimentos. Na contramão de um arquivo, cuja funcionalidade é meramente técnica, reunindo um conjunto de letras-mortas, defendemos a necessidade de lê-lo e também de escrevê-lo novamente, o que possibilita sua repetição, "entendida como movimento real, em oposição à representação" (DELEUZE, 1988, p.75).

Trata-se de repetir o "irrecomeçável” (DELEUZE, 1988, p.22), pois não há arquivo que não dependa de uma técnica de repetição. Portanto, todo arquivo tem como procedência a invenção, o que consiste em "repetir, reproduzir, cada vez em sua unicidade original, pois um arquivo deve ser idiomático, e ao mesmo tempo ofertada e furtada à tradução" (DERRIDA, 2001, p.118).

\begin{tabular}{|c|c|}
\hline ducação Temática Digital & Campi \\
\hline
\end{tabular}


Uma tradução não apenas incorreta errada; mais do que isso: desastrada. Escrevo tentando traduzir entre as línguas idênticas, o que li, mas falho, daí a criatividade; invenção como falha evidente, não na repetição, mas na tentativa de passagem de uma coisa para outro lado. Perdi algo na passagem, no transporte, isto é, ganhei algo, porque a mesa que perde uma das suas quatro pernas numa mudança imobiliária inventa no mesmo instante, um outro objeto com três pernas (TAVARES, 2012, p.61).

A cada leitura, engendra-se um novo texto; para que isso aconteça, é preciso, conforme Barthes (2012), decretar a morte do autor para celebrar a vida nova do texto, concedida pelo leitor, que também é um escritor. Nesse sentido, o tradutor (leitor-eescritor), ao recriar os elementos originais, é considerado criador em relação aos arquivos didáticos. De qualquer modo, o texto não é visto como um mensageiro da verdade, tampouco como um transmissor apressado de sentido. O texto é tomado, a partir da noção dada por Barthes (2012, p.62), como "espaço de dimensões múltiplas, onde se casam e se contestam escrituras variadas, das quais nenhuma é original”.

A didática, por sua vez, está intimamente vinculada a processos tradutórios dos arquivos. Essa didática entoa um canto paralelo ao texto original, o que se desenvolve por meio de um movimento plagiotrópico. Refere-se a processos inventivo-tradutórios que reformulam os arquivos cada vez que são postos na esteira tradutória. Daí emerge uma didática efetivamente marcada pelo trânsito entre o texto original e a transcriação, que não apenas vivifica o original, mas interfere de maneira afirmativa na prática docente, pois o educador-tradutor "vampiriza, o que corresponderia à ideia de mutabilidade do original pela atuação crítica de sua tradução" (CAMPOS, 2013, p.217), e o transforma em outro texto.

Não há dúvidas de que a ação de recriar o arquivo via tradução propicia ao educador-tradutor o "gesto variável de subordinações enunciativas de blocos, de idas e vindas de dobras e redobras da tópica e da reunião e da articulação" (DINARTE, 2016, p.12). Nesse gesto tradutório de arquivos didáticos, o educador-tradutor cria novos arquivos, "para além do literalismo rudimentar e da banalidade explicativa", como enfatiza Corazza (2013, p. 219). E criando novos arquivos Ihes dá nova vida. Tal fazer do educador-tradutor vale-se de traduções didáticas alternadas e apuradas que "poderão, por vezes, tornar-se mais importantes que os originais", pois a tradução se configura como uma "estratégia de renovação dos sistemas educacionais e culturais contemporâneos" (CORAZZA, 2013, p.219).

No encontro entre o educador e o arquivo didático, as matérias são atualizadas, reinventadas e traduzidas. Dessa atualização, constituem-se novas relações entre o conteúdo e a expressão do texto. Essas relações configuram uma prática inventivotradutória, exigindo do educador-tradutor um trabalho que se faz por necessidade, além do prazer investigativo da errância, sempre aberto ao inusitado.

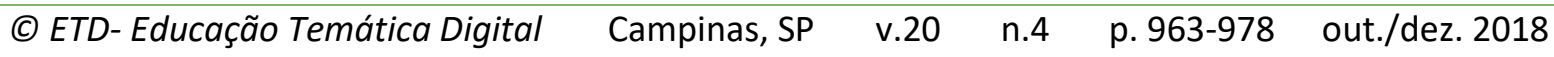


É notável que a tradução voltada ao remanejamento do que existe se configura como um desafio ao educador-tradutor: o de criar dispositivos que subvertem o modelo da imagem dogmática do pensamento. Um desses dispositivos refere-se às práticas de ler e de escrever de modo crítico mediante o exercício pensamental eminentemente tradutório, capaz de dar uma sobrevida ao texto original.

$\mathrm{O}$ arquivo, como texto aberto, corresponde a uma espécie de superfície porosa onde é possível transcrever as combinações entre as matérias, sendo também possível evocá-las na forma de eco fictício no momento em que o educador-tradutor lança mão de uma leitura e escrita tradutórias.

Cabe enfatizar que, nesse lugar chamado de cotidiano educacional, o educador, além de textos, traduz a própria vida, como potência ou movimento de criação, almejando que a existência possa ser concebida como arte. Logo, concordamos com a passagem de Valéry (1977, p.217) expressa em seus Cahiers: "a arte não é nada mais do que um pedagogo, porém mais importante - , pois ela pode me ensinar a dispor do meu espírito para além de suas aplicações práticas".

Nesse sentido, o educador-tradutor escreve vivendo; ele espreita a realidade e sobre ela levanta novos problemas que promovem no espírito dobras sobre si mesmo, num fazer poético-criador em elaboração constante. Visto que "vivemos do instável, pelo instável, no instável: essa é a função completa da Sensibilidade, que é a mola diabólica da vida dos seres organizados" (VALÉRY, 2011, p. 83). Trata-se de um modo de existir intensivo de vida que toma o vivível como matéria de pesquisa, para assim transmutá-la, transformá-la, por intermédio de nossa sensibilidade.

Portanto, a didática (AICE) é tomada pelo processo operatório de mutabilidade do original, que funciona ao "tomar de empréstimo ou roubar seus predecessores e contemporâneos" - é como "acender sua própria luz no topo da montanha" (CAMPOS, 2008, p.76). É por isso, e não por outra razão, que o educador-tradutor é considerado um antropófago, pois, ao alimentar-se de empréstimos de outrem, se nutre da força e da bravura alheia, as quais Ihe renovam as forças do espírito.

\section{O FAZER POÉTICO}

No âmbito de nossas pesquisas dentro das Filosofias da Diferença em Educação, não se concebe a docência sem o movimento empírico da pesquisa. Elas andam juntas como força potencial do próprio devir-vida e do fazer docente. Como salienta Corazza (2013, p.94), o "ensinar (fazendo pesquisa) e pesquisar (ensinando) consistem, dessa maneira, em criar soluções e, ao mesmo tempo, enigmas".

\begin{tabular}{|c|c|}
\hline Educação Temática Digital & o 963-978 \\
\hline
\end{tabular}


Trata-se de um convite conjunto com Valéry para: estudos e práticas educativas com ênfase na escrita e na leitura - mediante as aventuras do intelecto-, que propiciam ao educador-tradutor construir a sua própria realidade no campo ambiental da linguagem. Em tal ambiente, os conceitos de percepção e de criação tornam-se dois meios possíveis para movimentos experimentais do pensar, que visam a falar e escrever sobre Autor, Infância, Currículo e Educador - unidades analíticas referidas como AICE (Didática). Uma empiria didática que, via um mecanismo - operatório e conceitual - , dá impulso ao pensar exploratório, recusando a intervenção do juízo, desconstruindo os saberes constituídos para criar uma nova escrita por vir.

À medida que o educador-tradutor desconstrói velhos conceitos, exige uma nova construção que transmuta a forma de AICE; isso leva os espíritos pesquisadores a serem surpreendidos durante todo o processo, criando, nesses exercícios espirituais, "a potência própria de quem estuda uma literatura menor, educa uma infância informe, vive um impessoal devir-docente e formula currículos nômades" (CORAZZA, 2010, p.4) que são postos em movimento por meio de um nomadismo intelectual, experimentado no próprio território da educação. Trata-se de procedimentos múltiplos de escrita que possibilitam um fazer tradutório em educação.

Assim, criam-se condições para uma docência tradutória que propicia lidar com o ainda não visto, exercitando as impressões visuais que se demoram nas sensações, criando uma visão singular e axiológica para o ainda não significado, interpretado ou atribuído de valor. Ou seja, professor-pesquisador toma um determinado arquivo de partida, que na medida em que é manipulado no espaço-aula, constituí-se em um novo artigo singular. Pois na medida em que este arquivo é revisitado coloca em movimento uma "didática-crítica vivificadora", que "revolve as entranhas dos elementos artísticos, científicos e filosóficos (arquivo de partida) para trazê-los novamente à baila em outros corpos linguísticos" (CORAZZA, 2013, p.218), isto é um arquivo novo, atualizado ou transcriado.

Essa atividade de educar, que é também ação de manejar palavras, como diz Huxley (1981, p.43), é um aprender que retira a lente "semiopaca das ideias" dogmáticas e de lugar-comum, intensificando a capacidade de olhar o mundo aventureiramente e de intempestivamente escrever, como afirma Corazza (2006), para revigorar os modos de expressão da educação.

Com as Filosofias da Diferença, buscamos uma prática poética e tradutória que se utiliza do conhecimento como invenção, ou seja, faz da própria tradução uma prática literária. Esse movimento potencializa-se, na medida em que faz atuar e operar espíritos na educação que procuram inventar um possível e permissivo operar de uma consciência de si

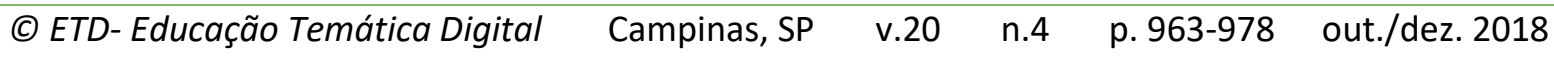


com relação aos movimentos do intelecto que seja ampla, isto é, com a procura do uso mais pleno das faculdades intelectivas de um sujeito que lê e escreve. Valéry, quando escreve o ensaio sobre Variations sur les Bucoliques de Virgílio, diz já na introdução:

O poeta é uma espécie singular de tradutor que traduz o discurso ordinário, modificado por uma emoção, em linguagem dos deuses; e seu trabalho interno consiste menos em buscar palavras para suas ideias do que em buscar ideias para suas palavras e seus ritmos preponderantes (VALÉRY, 1955, p.26)

Essas forças operativas em processo servem como impulso para uma trajetória autoconsciente do espírito que se aventura entre rasuras, que almeja o novo e, por isso, produz uma escrita aberta, sujeita a interações e oscilações oriundas de um espírito que age sobre o texto. Nessa perspectiva, interessa ao educador-tradutor uma didactique da novidade, da errância da docência, que pode gerar intranquilidade, desassossego e inquietude no que está posto como verdade no campo da educação.

Os movimentos tradutórios visam à recriação poética via processos de releitura e de reescrita do vivível no campo educacional. Esses movimentos produzem um currículo e uma didática da diferença, uma vez que criam novas epistemologias educacionais, possibilitando "pensar uma didática e um currículo tradutórios" (CORAZZA, 2014, p.5).

Devido a esses processos eminentemente tradutórios, e pela insistência no educar como prática tradutória; buscamos em Valéry lumes procedimentais potentes de seus escritos, que como faíscas são lançadas sobre a escuridão labiríntica do ainda não descoberto pelo pensamento. Procedimentos que oscilam entre o riso e o risível, em um constante fazer intercambiável de sensações despertas; capazes de criar, por esses mecanismos metamorfoseantes do espírito - que se colocam em movimento - um personagem que cultua a ação rigorosa do intelecto, para desse modo viver e "maquinar a educação, com prazer aventureiro e espírito aventuroso" (CORAZZA, 2014, p.5).

Tal aventura do espírito é possível por meio de uma self-variance escrileitora a produção de nova escrita potente, traduzindo, das matérias originais da arte, da ciência, da filosofia, da literatura e da educação, pontos relevantes para uma cena dramática; em uma aula como processo, ela se encontra afeita aos vigores vitais da comédia do intelecto.

Esse movimento que se serve da linguagem e que pressupõe pensar o educadortradutor como leitor-escritor toma força ao inserir-se marcando lugar no espaço-aula. Tratase de um teatro vivo que coloca em cena personagens ímpares que passam a atuar na cenaauleira como em um tablado flutuante que o educador-tradutor coloca sobre as águas oceânicas na contemporaneidade educacional.

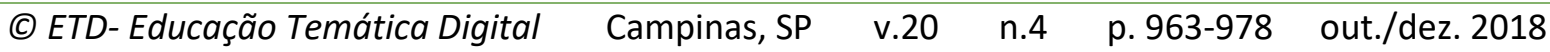


Nesse lugar - espaço-aula -, o educador-tradutor faz emergir o que diverge, pois tal encenação, composta por conteúdos curriculares, passa a servir de meio para novas invenções, assim recriando culturas e discursos por interventivos exercícios de perseverança do pensamento que transitam tanto pelo cômico quanto pelo dramático. Como um jogo que se joga no exercício do magistério, tem-se um operar mutante que atravessa a ortodoxia dos textos (CORAZZA, 2014) e com eles passar a criar, de modo próprio, uma docência indomesticada, crítica e vivificadora.

Visto a partir da perspectiva valéryana, o espírito do educador-tradutor, por meio dos movimentos de escrileitura - com o artifício da literatura - , movimenta sua malha intelectiva, possibilitando a construção de novas operações intelectivas, repletas de afecções. Permite e compõe um método do informe, um mecanismo que exige construção em que o inesperado é condição do processo. Trata-se, então, de utilizar o método do informe, que leva em conta a self-variance (autovariação de si) espiritual para falar e escrever sobre educação.

Valéry toma o pensamento como um modo privilegiado de dar especial atenção às invenções do intelecto - a partir de um Eu-função, pode-se desenvolver uma consciência do processo do pensar para fins de conhecimento. Ou seja:

\footnotetext{
Pensar está na ordem da ficcionalização e construção de realidades que são, cada uma ao seu modo, sempre inventadas, assim como aquilo que se sabe de si, do mundo e suas relações. No âmbito da Educação Contemporânea, especialmente no que tange à prática de ensino, esse pensamento ganha e doa força na medida em que se toma esse Eu-função como um modo de operar a singularização e não individualização. O que se conforma pelo processo de um Eu-função, como veremos adiante, é uma singularidade e não uma identidade. Quando há uma identidade possível na relação entre indivíduos ela, jamais, pode ser prevista antes da relação e tampouco pode ser estabilizada imediatamente depois. Não há identidade fora de qualquer relação, deste modo o que importa não é a identificação - exercício homogeneizador de diferenças por meio da distinção de iguais - , mas, justamente, a potência da singularização na atuação das relações entre indivíduos (ADÓ; CAMPOS; CORAZZA, 2015, p.2).
}

Nesse sentido, interessam ao educador-tradutor os procedimentos operativos de escrileituras, abertos ao esforço da criação, à variação intelectiva, mediante um fazer escrileitor que encontra um manancial fértil para a produção de uma educação eminentemente tradutória de arquivos didáticos que se movem entre leituras e escritas. Isto é, o espírito prepara-se para escrever e observa o próprio fazer da escrita literária, que tem como tarefa: anotar, borrar, fazer múltiplas reflexões, combinações, tentativas e falhas. 


\section{CONSIDERAÇÕES FINAIS}

O educador-tradutor, em meio a uma ação funcional de ação geométrica e mutante, abre uma passagem contagiosa cujo efeito estimula o fazer na docência. Uma prática atravessada por linhas ondulantes de leitura e de escrita tradutórias, capaz de elaborar estratégias significativas de pensar e viver e de dar vida a uma nova práxis de ensino. Como em uma geometria única que mede o mundo, o educador-tradutor traça linhas existenciais vivíveis e de itinerários singulares à educação. De acordo com Valéry,

Escrever o que quer que seja, desde o momento em que o ato de escrever exige reflexão, e não é uma inscrição maquinal e sem detenças de uma palavra interior toda espontânea, é um trabalho de tradução exatamente comparável àquele que opera a transmutação de um texto de uma língua em outra (VALÉRY apud CAMPOS, 2013, pág.61-62).

Enfim, podemos observar que as práticas tradutórias de escrileituras propiciam ações potentes no campo da educação, pois tratam de reimaginar os arquivos didáticos, sempre mutantes e abertos a novas interferências. De toda maneira, cabe aos educadorestradutores novos modos de recriar os arquivos didáticos e, com isso, mostrar, a partir do que existe, o que ainda pode ser feito como novidade, como renovação na pesquisadocência.

À sua maneira, o educador-tradutor inventa novos arquivos com uma vontade de existência poética para o que se pode ainda fazer com eles. Não há dúvidas de que se trata, portanto, de uma fome antropofágica de apetite voraz que impregna o espírito aventuroso e incita a processos tradutórios que se distanciam dos automatismos, dando maior fluidez aos pensamentos e, com eles, a alegria que se coloca em cena no vivível cotidiano do magistério.

\section{REFERÊNCIAS}

ADÓ, Máximo Daniel L; CAMPOS, Maria Idalina Krause de; CORAZZA, Sandra Mara. Conhecimento como invenção: Paul Válery no ensino da educação contemporânea.

Educação por escrito. Porto Alegre: v.6, n.1, jan./jun. 2015. Disponível em: http://revistaseletronicas.pucrs.br/ojs/index.php/porescrito/article/view/17787/12796 Acesso em: 20 jun. 2017.

BARTHES, Roland. A preparação do romance II: a obra como vontade: notas de curso no Collège de France 1979-1980. Tradução Leyla Perrone-Móises. São Paulo: Martins Fontes, 2005. 475 p. ISBN 85-336-2200-7.

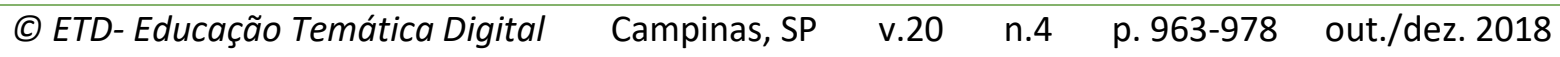


BARTHES, Roland. O rumor da língua. 3. ed. Tradução Mário Laranjeira. São Paulo: Martins Fontes, 2012. 462 p. ISBN 978 -85-7827-498-6.

BIRMAN, Joel. O arquivo e o mal de arquivo: uma leitura de Derrida de Freud. Revista Natureza Humana, v.10, n.1, 2008. Disponível em:

http://pepsic.bvsalud.org/pdf/nh/v10n1/v10n1a05.pdf. Acesso em: 20 jun. 2017.

CAMPOS, HAROLDO de. Deus e o diabo no Fausto de Goethe. São Paulo: Perspectiva, 2008. 209 p. ISBN 978-85-273-0450-4.

CAMPOS, HAROLDO de. Haroldo de Campos - Transcriação. São Paulo: Perspectiva, 2013. 256 p. ISBN: 978-85-273-0985-1.

CORAZZA, Sandra Mara. O que se transcria em educação? Porto Alegre: UFRGS; Doisa, 2013. 228 p. ISBN 978-85-66308-03-7.

CORAZZA, Sandra Mara. Didática da Tradução, Transcriação do Currículo: Escrileituras da Diferença. Projeto de Pesquisa (Produtividade), apresentado ao CNPq em janeiro de 2015. 41p. (Texto digitalizado)

CORAZZA, Sandra Mara. Dramatização do infantil na comédia intelectual do currículo: método Valéry-Deleuze. Projeto de Pesquisa (Produtividade), apresentado ao CNPq em agosto de 2010. 91p. (Texto Digitalizado)

DELEUZE, Gilles. Diferença e repetição. Tradução Luiz B. L. Orlandi e Roberto Machado. Rio de Janeiro: Graal, 1988.499 p.

DELEUZE, Gilles. Foucault. Tradução Claudia Sant'Anna Martins. São Paulo: Brasilense, 2005. 142 p. ISBN 85-11-12050-5

DELEUZE, Gilles. Conversações. Tradução Peter Pál Pelbart. 3. ed. São Paulo: Ed. 34, 2013. 240 p. ISBN 978-85-85490-04-1

DELEUZE, Gilles; PARNET, Claire. Diálogos. Tradução Eloisa Araújo Ribeiro. São Paulo: Escuta, 1998.179p. ISBN: 85-7137-127

DERRIDA, Jacques. Mal de arquivo: uma impressão freudiana. Tradução Claudia de Moraes Rego. Rio de Janeiro: Relume Dumará, 2001. 130 p. ISBN 978-85-7316-247-9

DINARTE, Luiz Daniel Rodrigues. Congresso dos Signais. Didática filosófica do gesto. 2016. Proposta de Tese (Doutorado em Educação). Programa de Pós-Graduação em Educação, Faculdade de Educação, Universidade Federal do Rio Grande do Sul, Porto Alegre, 2016.

FARGE, Arlete. O sabor do arquivo. Tradução Fátima Murad. São Paulo: Ed. USP, 2009. 120 p. ISBN 978-85-314-1167-0

FONSECA, Tania Maria Galli. Vidas do Fora e a escrileitura de um mundo incontável. In: . ; COSTA, Luciano Bedin da. Vidas do fora: habitantes do silêncio. Porto Alegre: Ed. UFRGS, 2010. 383 p.

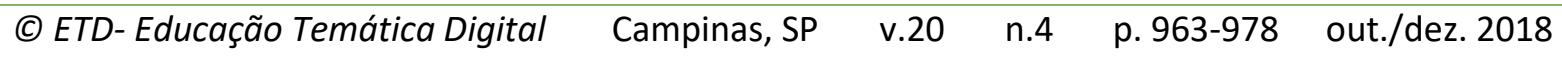


HUXLEY, Aldous Leonard. As portas da percepção e, céu e inferno. Tradução Osvaldo de Araujo Souza. 10.ed. Rio de Janeiro: Globo, 1981. 116 p. ISBN 615.78830924

OLIVEIRA, Marcos Rocha. Método da dramatização da aula: o que é a pedagogia, a didática, o currículo. 2014. Tese (Doutorado em Educação). Programa de Pós-Graduação em Educação, Faculdade de Educação, Universidade Federal do Rio Grande do Sul, Porto Alegre, 2014.

PAZ, Octavio. Tradução, literatura e literalidade. Edição bilíngue. Tradução Doralice Alves de Queiroz. Belo Horizonte: FALE/UFMG, 2009. Disponível em:

http://150.164.100.248/vivavoz/data1/arquivos/traducao2ed-site.pdf Acesso em: 20 jun. 2017.

TADEU, Tomaz; CORAZZA, Sandra Mara; ZORDAN, Paola. Linhas de escrita. Belo Horizonte: Autêntica, 2004. 206 p. ISBN 85-7526-125-8

TAVARES, Gonçalo. Breves notas sobre a ciência; breves notas sobre o medo; breves notas sobre as ligações. Relógio D' Água, 2012. 298 p. ISBN 978-989-641-332-3

VALÉRY, Paul. Variations sur les Bucoliques. Traduction en vers des Bucoliques de Virgile. Paris: NRF, 1955. $154 \mathrm{p}$.

VALÉRY, Paul. Cahiers. Paris: Gallimard, 1977. 320 p. ISBN 2070296466.

VALÉRY, Paul. Variedades. Trad. Maiza Martins de Siqueira. São Paulo: Iluminuras, 2011. 83 p. ISBN 85-7321-234-9.

* Revisão gramatical do texto sob responsabilidade de:

Lene Leblon - E-mail: leneleblon@hotmail.com 